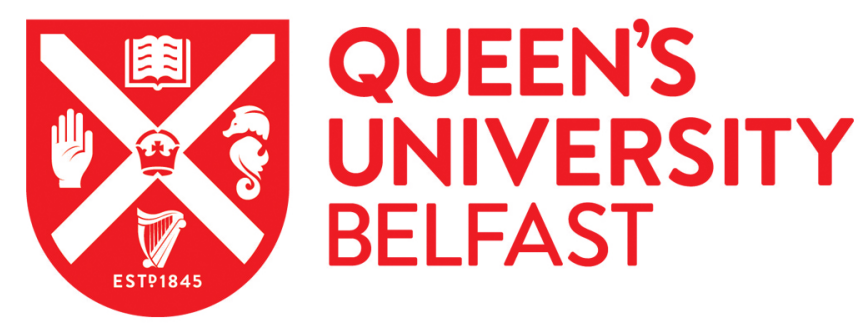

\title{
Dissecting the binding interactions of teixobactin with the bacterial cell wall precursor lipid II
}

Chiorean, S., Antwi, I., Carney, D., Kotsogianni, I., Giltrap, A., Alexander, F. M., Cochrane, S. A., Payne, R., Martin, N., Henninot, A., \& Vederas, J. (2019). Dissecting the binding interactions of teixobactin with the bacterial cell wall precursor lipid II. ChemBioChem. https://doi.org/10.1002/cbic.201900504

\section{Published in:}

ChemBioChem

\section{Document Version:}

Peer reviewed version

Queen's University Belfast - Research Portal:

Link to publication record in Queen's University Belfast Research Portal

Publisher rights

( 2019 WILEY-VCH Verlag GmbH \& Co. KGaA, Weinheim. This work is made available online in accordance with the publisher's policies. Please refer to any applicable terms of use of the publisher.

\section{General rights}

Copyright for the publications made accessible via the Queen's University Belfast Research Portal is retained by the author(s) and / or other copyright owners and it is a condition of accessing these publications that users recognise and abide by the legal requirements associated with these rights.

Take down policy

The Research Portal is Queen's institutional repository that provides access to Queen's research output. Every effort has been made to ensure that content in the Research Portal does not infringe any person's rights, or applicable UK laws. If you discover content in the Research Portal that you believe breaches copyright or violates any law, please contact openaccess@qub.ac.uk. 


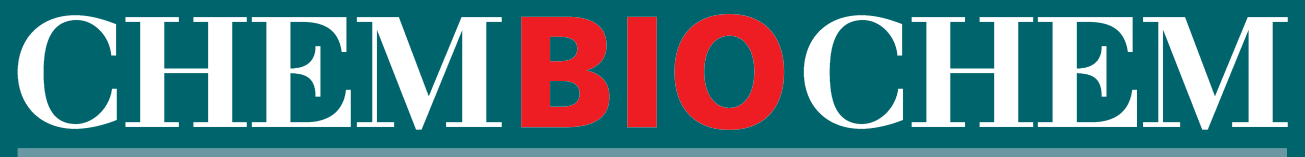

SYNTHETIC BIOLOGY \& BIO-NANOTECHNOLOGY

\section{Accepted Article}

Title: Dissecting the binding interactions of teixobactin with the bacterial cell wall precursor lipid II

Authors: Sorina Chiorean, Isaac Antwi, Daniel W Carney, Ioli Kotsogianni, Andrew M Giltrap, Francesca M Alexander, Stephen A Cochrane, Richard J Payne, Nathaniel I Martin, Antoine Henninot, and John Christopher Vederas

This manuscript has been accepted after peer review and appears as an Accepted Article online prior to editing, proofing, and formal publication of the final Version of Record (VoR). This work is currently citable by using the Digital Object Identifier (DOI) given below. The VoR will be published online in Early View as soon as possible and may be different to this Accepted Article as a result of editing. Readers should obtain the VoR from the journal website shown below when it is published to ensure accuracy of information. The authors are responsible for the content of this Accepted Article.

To be cited as: ChemBioChem 10.1002/cbic.201900504

Link to VoR: http://dx.doi.org/10.1002/cbic.201900504 


\title{
Dissecting the binding interactions of teixobactin with the bacterial cell wall precursor lipid II
}

\author{
Sorina Chiorean, ${ }^{[\mathrm{a}]}$ Isaac Antwi, ${ }^{[\mathrm{a}]}$ Daniel W. Carney, ${ }^{[\mathrm{b}]}$ Ioli Kotsogianni, ${ }^{[\mathrm{c}]}$ Andrew M. Giltrap, ${ }^{[\mathrm{d}]}$ \\ Francesca M. Alexander, ${ }^{[\mathrm{e}]}$ Stephen A. Cochrane, ${ }^{[\mathrm{e}]}$ Richard J. Payne,${ }^{[\mathrm{d}]}$ Nathaniel I. Martin, ${ }^{[\mathrm{c}]}$ Antoine \\ Henninot, ${ }^{[b]}$ and John C. Vederas ${ }^{\star[a]}$
}

\begin{abstract}
The prevalence of life-threatening, drug resistant microbial infections has challenged researchers to consider alternatives to currently available antibiotics. Teixobactin is a recently discovered "resistance proof" antimicrobial peptide that targets the bacterial cell wall precursor lipid II. In doing so, teixobactin exhibits potent antimicrobial activity against a wide range of Gram-positive organisms. Here we demonstrate that teixobactin and several structural analogues are capable of binding lipid II from both Grampositive and Gram-negative bacteria. Furthermore, we show that when combined with known outer membrane-disrupting peptides, teixobactin is active against Gram-negative organisms.
\end{abstract}

The growing threat of antibiotic resistance has led to the speculation that the twenty-first century may witness the arrival of a post-antibiotic era in medicine, wherein antimicrobial resistance is developing faster than before and the longevity of currently effective antibiotics is shortened. ${ }^{[1]}$ To address this growing concern, researchers have embarked on the search for antibiotics with new mechanisms of action and potential longer lasting therapeutic lifetimes. A promising avenue lies in exploring natural products produced by microbial cultures; with particular interest in peptides which have innate antimicrobial activity and act upon a variety of targets due to the versatility of amino acid building blocks. ${ }^{[2-4]}$ An example of such peptide natural product is teixobactin (Figure 1a). This molecule was recently uncovered using the so-called iChip technology and found to have potent activity against a broad range of Gram-positive organisms, including methicillin-resistant Staphylococcus aureus (MRSA), vancomycin-resistant enterococci (VRE), and Mycobacterium tuberculosis. ${ }^{[5]}$ Teixobactin is a non-ribosomally synthesised depsipeptide composed of 11 amino acids, including four Damino acids and the unique cyclic guanidine containing amino acid L-allo-enduracididine (allo-End), a methylated N-terminus, and a cyclized C-terminus. In addition to these interesting structural features, a key attraction of the molecule was that all attempts to induce laboratory resistance in $S$. aureus and $M$. tuberculosis strains were unsuccessful. ${ }^{[5]}$ Teixobactin's activity could be extended to an Escherichia coli strain (asmB1) with a

[a] Sorina Chiorean, Isaac Antwi, Prof. John C. Vederas* Department of Chemistry, University of Alberta, Edmonton, Alberta, Canada, T6G 2G2

*E-mail: john.vederas@ualberta.ca

[b] Dr. Daniel W. Carney, Dr. Antoine Henninot

Ferring Research Institute, Inc. San Diego, California, USA, 92121

[c] Ioli Kotsogianni, Prof. Nathaniel I. Martin

Biological Chemistry Group, Institute of Biology Leiden, Leiden University, Sylviusweg 72, 2333 BE Leiden, NL

[d] Dr. Andrew M. Giltrap, Prof. Richard J. Payne

School of Chemistry, University of Sydney, NSW 2006, AU

[e] Francesca M. Alexander, Prof. Stephen A. Cochrane

School of Chemistry and Chemical Engineering, Queen's University, Belfast, UK, BT9 5AG

Supporting information and the ORCID identification numbers for the authors of this article can be found under *link ${ }^{*}$ severely damaged outer membrane. ${ }^{[5]}$ Interest in the peptide's activity and therapeutic potential led to curiosity in synthetic approaches to access teixobactin; with two distinct synthetic routes reported just a year later. ${ }^{[6,7]}$ Following the initial report, several studies were aimed at understanding the spectrum of antimicrobial activity, ${ }^{[8,9]}$ structure-activity studies, ${ }^{[10-12]}$ and interrogating the mode of action through modelling, ${ }^{[13,14]}$ and structural investigations. ${ }^{[15,16]}$ These studies yielded insights into key residues, modifiable regions, and suspected binding sites of teixobactin to its cellular targets - the bacterial cell wall precursors: lipid II (Figure 1b) and lipid III. To date, the mechanism of action of teixobactin has not been fully uncovered, although evidence suggests amyloid-like aggregation after binding to lipid II may play a significant role in the antimicrobial activity. ${ }^{[15]}$

a.

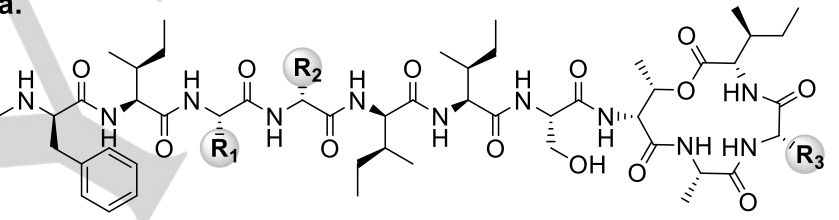

1 Teixobactin

$\mathrm{R}_{1}:$ Ser, $\mathrm{R}_{2}: \mathrm{D}-\mathrm{Gln}, \mathrm{R}_{3}$ :allo-End

$2\left[\operatorname{Arg}_{10}\right]$ Teixobactin

$\mathrm{R}_{1}:$ Ser, $\mathrm{R}_{2}: \mathrm{D}-\mathrm{Gln}, \mathrm{R}_{3}:$ Arg

3 [Lys 10 ] Teixobactin

$\mathrm{R}_{1}$ :Ser, $\mathrm{R}_{2}$ :D-Gln, $\mathrm{R}_{3}:$ Lys

4 [ Lys $_{3}$ Lys $_{10}$ ] Teixobactin $\quad R_{1}:$ Lys, $R_{2}: D-G l n, R_{3}:$ Lys

5 [D-Lys Lys $_{10}$ ] Teixobactin $R_{1}$ :Ser, $R_{2}$ :D-Lys, $R_{3}$ :Lys

b.

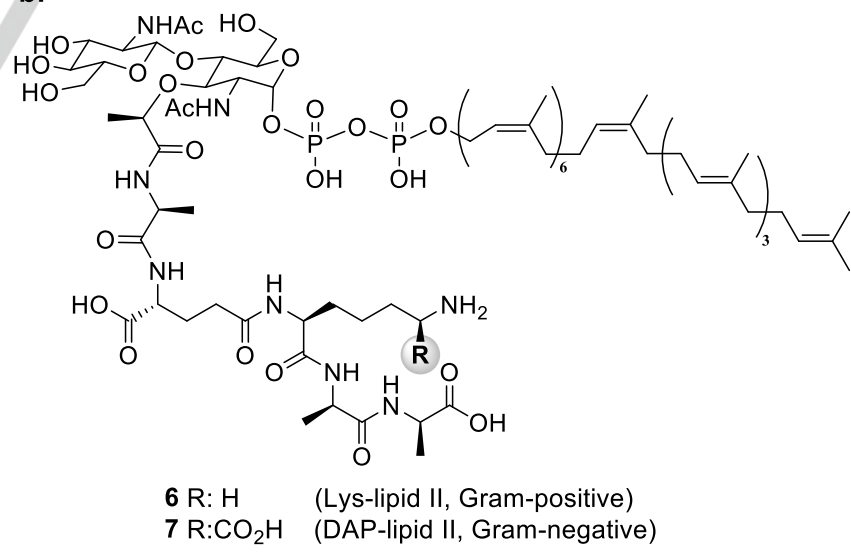

Figure 1. Structures of a. teixobactin and its structural analogues under study and b. native lipid II variants of Gram-positive and Gram-negative bacteria.

To further understand the mechanisms of teixobactin binding, we embarked on studies investigating the relationship between teixobactin and several synthetic analogues (Figure 1a) and that of lipid II variants using isothermal titration calorimetry (ITC), which has been successfully used to study lipid II interactions with other antimicrobial peptides. ${ }^{[17,18]}$ Due to the rarity of the allo-End residue and solubility issues associated with teixobactin

For internal use, please do not delete. Submitted_Manuscript 
(1), more readily accessible and water soluble analogues were chosen for this study. Lipid II binding by native teixobactin, as well as four synthetic analogues, was initially tested against the Gram-positive lipid II variant, which was synthesized as previously reported ${ }^{[19]}$ and contains lysine at the 3-position of the pentapeptide (Figure 1b), the results of which are provided in Table 1. Teixobactin analogue $\mathbf{3}$, in which the enduracididine was replaced by the lysine, binds Gram-positive lipid II as strongly as native teixobactin (1), with $\mathrm{K}_{d}$ values of $0.60 \mu \mathrm{M}$ and $0.43 \mu \mathrm{M}$, respectively. It should be noted that ITC was also performed with teixobactin and Gram-positive lipid II in large unilammelar vesicles and these trials provided analogous results, with a $\mathrm{K}_{d}$ of $0.10 \mu \mathrm{M}$ (Supplementary Table S1). In contrast, analogue 2 , where arginine has replaced the native enduracididine residue, binds lipid II with a ten-fold weaker affinity than parent natural product $\left(K_{d} 4.1 \mu \mathrm{M}\right)$. The Gramnegative lipid II binding of the other two analogues investigated (with Ser to Lys substitution in position 3 or D-GIn to D-Lys in position 4 of the linear tail of teixobactin) was approximately 100 -fold weaker, with dissociation constants of $63 \mu \mathrm{M}$ and 38 $\mu \mathrm{M}$ for analogues $\mathbf{4}$ and $\mathbf{5}$, respectively. These analogues were designed with the results from the Albericio group in mind, which showed that positions 3 and 4 Lys substitutions are tolerated and activity is largely maintained. ${ }^{[20]}$

Table 1. Binding Parameter $\mathrm{K}_{d}(\mu \mathrm{M})$ of Teixobactin Analogues and Lipid II

\begin{tabular}{cccccc}
\hline Compound & $\begin{array}{c}\text { Native } \\
\text { (1) }\end{array}$ & $\begin{array}{c}\operatorname{Arg}_{10} \\
\mathbf{( 2 )}\end{array}$ & $\begin{array}{c}\text { Lys }_{10} \\
\mathbf{( 3 )}\end{array}$ & $\begin{array}{c}\text { Lys }_{3} \text { Lys }_{10} \\
\mathbf{( 4 )}\end{array}$ & $\begin{array}{c}\mathrm{D}^{2} \mathrm{Lys}_{4} \mathrm{Lys}_{10} \\
\mathbf{( 5 )}\end{array}$ \\
\hline $\begin{array}{c}\text { Lys-lipid II } \\
\mathbf{( 6 )}\end{array}$ & 0.43 & 4.13 & 0.60 & 63.01 & 37.86 \\
$\begin{array}{c}\text { DAP-lipid II } \\
\text { (7) }\end{array}$ & 1.36 & 0.06 & 0.90 & 1.68 & 2.30 \\
\hline
\end{tabular}

Table indicating the average dissociation constant $(\mu \mathrm{M})$ obtained from the isothermal calorimetry trials. Deviations range from $27.17 \mu \mathrm{M}$ to $1.7 \mathrm{nM}$.

Building upon these results with the Gram-positive lipid II, we next turned our attention to the Gram-negative variant of lipid II containing diaminopimelic acid (DAP) in place of lysine in the pentapeptide motif (7). This extra carboxylic acid may play a role in binding by providing an additional hydrogen bond acceptor and donor. Specifically, teixobactin analogues 2 and 3, which both contain a free amino group, were found to be the tightest Gram-negative lipid II binders with $\mathrm{K}_{d}$ values of $0.06 \mu \mathrm{M}$ and $0.90 \mu \mathrm{M}$, respectively. Notably, native teixobactin binds to Gramnegative lipid II with a weaker affinity, with a measured $K_{d}$ value of $1.36 \mu \mathrm{M}$. This was similar to the dissociation constants measured for analogues 4 and $\mathbf{5}\left(\mathrm{K}_{\mathrm{d}}\right.$ values of 1.68 and 2.30 $\mathrm{mM}$, respectively).

To further probe the key binding interactions of teixobactin, the analogues were also assessed against a series of synthetic truncated lipid II analogues (see Supplementary Figure S1 and Table S1). In line with previously reported results, ${ }^{[5]}$ we found that phospholipids bearing an unsubstituted pyrophosphate bind with teixobactin nearly as well as the full length Gram-positive lipid II molecule. Binding studies with native teixobactin and undecaprenyl pyrophosphate $\left(\mathrm{C}_{55}-\mathrm{PP}, 13\right)$ revealed a $\mathrm{K}_{\mathrm{d}}$ value of $0.82 \mu \mathrm{M}$. By comparison, teixobactin binding to monophosphate lipids was significantly reduced with $\mathrm{K}_{d}$ values of $7.69 \mu \mathrm{M}$ for undecaprenyl phosphate $\left(\mathrm{C}_{55}-\mathrm{P}, 10\right)$ and $11.26 \mu \mathrm{M}$ for the $Z, Z$ farnesyl phosphate $\left(Z, Z-C_{15}-P, 8\right)$. The pyrophosphate moiety is suspected to form intermolecular hydrogen bonds with the macrocycle of teixobactin, an evidently important interaction required for recognition and binding ${ }^{[15]}$ Attempts were made to elucidate the binding motifs of these interactions (pyrophosphorylated lipids with native teixobactin) using nuclear magnetic resonance (NMR). However, these experiments were not feasible in solution-phase as a compatible solvent for both the lipid and the peptide were not found, leading to solubility issues. Similar interactions were investigated using solid-phase NMR and were reported just last year. ${ }^{[15]}$

Table 2. Minimum Inhibitory Concentrations $(\mu \mathrm{g} / \mathrm{mL})$ of Teixobactin Analogues

\begin{tabular}{|c|c|c|c|c|}
\hline Organism & Teixobactin & Alone & H-TriA ${ }_{1}$ & PMBN \\
\hline \multirow{5}{*}{$\begin{array}{l}\text { Escherichia } \\
\text { coli } \\
\text { ATCC } 25822\end{array}$} & Native & 22.5 & 0.70 & 5.63 \\
\hline & $\operatorname{Arg}_{10}$ & 90 & 22.5 & 45 \\
\hline & Lys $_{10}$ & 45 & 22.5 & 22.5 \\
\hline & Lys $_{3}$ Lys $_{10}$ & 22.5 & 1.41 & 2.81 \\
\hline & D-Lys $\mathbf{L}_{4}$ Lys $_{10}$ & 22.5 & 11.3 & 22.5 \\
\hline \multirow{5}{*}{$\begin{array}{l}\text { E. coli } \\
\text { DH5a }\end{array}$} & Native & 22.5 & 2.81 & 5.63 \\
\hline & $\operatorname{Arg}_{10}$ & 45 & 11.3 & 22.5 \\
\hline & Lys $_{10}$ & 45 & 5.63 & 11.3 \\
\hline & Lys $_{3}$ Lys $_{10}$ & 22.5 & 1.41 & 2.81 \\
\hline & D-Lys $\mathbf{L}_{4}$ Lys $_{10}$ & 22.5 & 11.3 & 22.5 \\
\hline \multirow{5}{*}{$\begin{array}{l}\text { Salmonella } \\
\text { enterica } \\
\text { ATCC } 13311\end{array}$} & Native & 22.5 & 0.18 & 11.3 \\
\hline & $\operatorname{Arg}_{10}$ & 90 & 0.09 & 22.5 \\
\hline & Lys $_{10}$ & 45 & 0.09 & 22.5 \\
\hline & $\operatorname{Lys}_{3} \operatorname{Lys}_{10}$ & 22.5 & 0.70 & 11.3 \\
\hline & D-Lys Lys $_{10}$ & 22.5 & 1.41 & 5.63 \\
\hline \multirow{5}{*}{$\begin{array}{l}\text { S. enterica } \\
\text { ATCC } 23564\end{array}$} & Native & 45 & 11.3 & 5.63 \\
\hline & $\operatorname{Arg}_{10}$ & - & 11.3 & 22.5 \\
\hline & Lys $_{10}$ & 90 & 22.5 & 22.5 \\
\hline & $\operatorname{Lys}_{3}$ Lys $_{10}$ & 22.5 & 5.63 & 11.3 \\
\hline & D-Lys $\mathbf{L}_{\mathbf{4}} \mathrm{Lys}_{10}$ & 22.5 & 5.63 & 5.63 \\
\hline \multirow{5}{*}{$\begin{array}{l}\text { Klebsiella } \\
\text { pneumoniae } \\
\text { ATCC } 13883\end{array}$} & Native & 45 & 5.63 & 11.3 \\
\hline & $\operatorname{Arg}_{10}$ & 45 & 1.41 & 22.5 \\
\hline & Lys $_{10}$ & 45 & 2.81 & 45 \\
\hline & $\operatorname{Lys}_{3} \operatorname{Lys}_{10}$ & 45 & 1.41 & 2.81 \\
\hline & D-Lys $\mathbf{L}_{4}$ Lys $_{10}$ & 45 & 1.41 & 45 \\
\hline
\end{tabular}

Table showing the average minimum inhibitory concentrations $(\mu \mathrm{g} / \mathrm{mL})$ obtained for each teixobactin analogue alone as well as synergistic treatment with H-TriA1 $(12.5 \mu \mathrm{g} / \mathrm{mL})$ and PMBN $(30 \mu \mathrm{g} / \mathrm{mL})$ for a selection of Gramnegative bacteria. A '-' indicates cases where the MIC was not observed at the highest soluble concentration of the teixobactin tested.

Given that teixobactin and its analogues were found to bind readily to the Gram-negative lipid II variant, yet do not possess strong antimicrobial activity against the Gram-negative organisms, we next sought to explore whether the combination 
of teixobactin with known Gram-negative outer membranedisrupting peptides would lead to improved antimicrobial activity. This strategy has proved successful for other molecules with a limited spectrum of activity against Gram-negative organisms, ${ }^{[21,22]}$ whereby the minimum inhibitory concentration (MIC) of the antimicrobial of interest is lowered when combined with outer membrane-disrupting peptides. To this end, two peptides, unacylated tridecaptin $\left(\mathrm{H}-\mathrm{TriA}_{1}\right)$ and polymyxin $B$ nonapeptide (PMBN) (see Supplementary Figure S3), were evaluated for the ability to synergize with teixobactin. For the synergistic assay, the same panel of teixobactin analogues were combined with $\mathrm{H}-\mathrm{Tri} \mathrm{A}_{1}$ or $\mathrm{PMBN}$ in increasing concentrations up to $12.5 \mu \mathrm{g} / \mathrm{mL}$ and $30 \mu \mathrm{g} / \mathrm{mL}$, respectively. In the presence of the outer membrane-disrupting peptides, nearly all strains tested were shown to be more sensitive towards the administered teixobactin (Table 2). Of the strains tested, Salmonella enterica ATCC 13311 proved to be most sensitive to teixobactin in combination with $\mathrm{H}$-TriA ${ }_{1}$. Most notable were the 125 -fold and 1024-fold reductions in MIC observed for native teixobactin and analogue 2 , respectively when tested in combination with $\mathrm{H}$ $\mathrm{TriA}_{1}$ at a concentration of $12.5 \mu \mathrm{g} / \mathrm{mL}$. Interestingly, the synergy observed for teixobactin and its analogues with PMBN was much less pronounced with MIC enhancements not exceeding an 8-fold reduction at the highest PMBN concentrations tested $(30 \mu \mathrm{g} / \mathrm{mL})$. Previous work has revealed that $\mathrm{H}-\mathrm{TriA}_{1}$ interacts with lipopolysaccharides in a concentration dependant manner while PMBN reaches a maximum concentration, or saturation point, after which additional PMBN does not bind to the same cell. ${ }^{[23]} \mathrm{A}$ more extensive data set and other MICs results can be found in Supplementary Table S2.

In summary, through a series of thermodynamic measurements, it was found that teixobactin and a series of synthetic analogues bind both Gram-positive and Gram-negative variants of lipid II with high affinity. Furthermore, in the presence of Gram-negative outer membrane-disrupting peptides, such as unacylated tridecaptin and polymyxin B nonapeptide, the activity of teixobactin against Gram-negative organisms can be dramatically enhanced. Notably, this can effectively lower the concentration of teixobactin needed to elicit antimicrobial affects against Gram-negative organisms while at concentrations below the solubility limitations of the peptide and its analogues. This information provides additional insights towards a more complete understanding of the mechanistic details involved in the mode of action of teixobactin through the binding of lipid. These findings will be valuable for the future design of new antibiotic leads based on the natural product teixobactin.

\section{Experimental Section}

Minimum inhibitory concentration determination. The MICs presented here were determined using microbroth dilution assays following the protocol of the Clinical and Standards Laboratory Institute. ${ }^{[24]}$ Antimicrobial peptides were dissolved in $\mathrm{MHB}$ and serial dilutions were made across a 96-well plate. Each plate was inoculated with the organism in question to reach a final inoculum of $5 \times 10^{5}$ colony forming units per $\mathrm{mL}$. Using $\mathrm{OD}_{600}$ readings normalized to a blank control, MICs were recorded as the lowest concentration at which no growth was detected after a $24 \mathrm{~h}$, or $48 \mathrm{~h}$ for $K$. pneumoniae, incubation.
Synergistic bioassays with outer membrane-disrupting peptides. Synergistic bioassays were conducted using an adjusted microbroth dilution assay mentioned above to observe the effects of unacylated tridecaptin $\left(\mathrm{H}-\mathrm{Tri}_{1}\right)$ and polymixin $B$ nonapeptide (PMBN). Serial dilutions of the teixobactin analogues were performed across 5 rows of a 96-well plate. To each row, $50 \mu \mathrm{L}$ were added of (A) sterile water, (B-E) increasing concentrations of outer membrane-disrupting peptides. $\mathrm{H}$ $\mathrm{TriA}_{1}$ was added in $1.56,3.13,6.25,12.5 \mu \mathrm{g} / \mathrm{mL}$ to rows (B-E), respectively; PMBN was added at concentrations of $3.25,7.5,15,30$ $\mu \mathrm{g} / \mathrm{mL}$ to rows (B-E), respectively. The last row $(F)$ contained the highest concentration of outer membrane-disrupting peptide without teixobactin. Each well was inoculated with the desired organism and the plates were incubated at the designated temperature. The MICs were determined using $\mathrm{OD}_{600}$ readings.

Isothermal titration calorimetry utilizing free in-solution lipids and peptides. Microcalorimetric experiments were performed on an MCS isothermal titration calorimeter (Microcal, Northampton, MA) at $25^{\circ} \mathrm{C}$ The lipid variant solution was prepared at a concentration of $100 \mu \mathrm{M}$ in Tris buffer $(10 \mathrm{mM}$ Tris $\mathrm{HCl}, 150 \mathrm{mM} \mathrm{NaCl}, \mathrm{pH}=6.5)$ and the teixobactin and teixobactin analogue solutions were prepared to $10 \mu \mathrm{M}$ in the same Tris buffer. Samples were degassed by stirring under vacuum at $20^{\circ} \mathrm{C}$ for 8 minutes immediately before use. The lipid solution was titrated into teixobactin solution using the following conditions: temperature $25{ }^{\circ} \mathrm{C}$, reference power $=25 \mu \mathrm{Cal} / \mathrm{s}$, syringe-stiring speed $=300 \mathrm{rpm}$, number of injections $=29$, injection volume $=10 \mu \mathrm{L}$, initial delay $=60 \mathrm{~s}$, and time between injections $=300 \mathrm{~s}$. The change in heat rate during each injection was registered in real time and raw data were processed using the software provided with the instrument, Origin ${ }^{\circ}$ 7. Control experiments were performed using a similar protocol in which the buffer solution was titrated into buffer solution and lipid II was titrated into buffer solution. Each experiment and control was performed in triplicate.

Isothermal titration calorimetry with symmetric incorporation of lipid II into artificial large unilammeral vesicles (LUVs). Dioleoyl phosphatidylcholine (DOPC) LUVs $(0.2 \mu \mathrm{m})$ as a control or $1 \mathrm{~mol} \%$ Gram-positive lipid II containing DOPC LUVs were prepared as previously described. ${ }^{[18]}$ LUV binding experiments were performed using a MicroCal PEAQ-ITC Automated microcalorimeter (Malvern). The samples are equilibrated to $25^{\circ} \mathrm{C}$ prior to the measurement. The vesicle suspension of $0.1 \mathrm{mM}$ Gram-positive lipid II, $10 \mathrm{mM}$ DOPC in $50 \mathrm{mM}$ Tris, $\mathrm{pH} 7.5$ was titrated into a freshly made solution of $20 \mu \mathrm{M}$ teixobactin in the same buffer. The titration is conducted under the following conditions: temperature $25^{\circ} \mathrm{C}$, reference power $=5 \mu \mathrm{Cal} / \mathrm{s}$, syringestirring speed $=1000 \mathrm{rpm}$, number of injections $=25$, injection volume $=$ $1.5 \mu \mathrm{L}$, and time between injections $=180 \mathrm{~s}$. The calorimetric data obtained was analysed using MicroCal PEAQ-ITC Analysis Software Version 1.20. Experiments and controls were performed in triplicate.

\section{Acknowledgements}

This work was supported by Ferring Pharmaceuticals Inc., the Natural Sciences and Engineering Research Council of Canada (NSERC), and the Australian National Health and Medical Research Council (Project grant 1141142). Financial support by Leiden University (fellowship to I.K.) and from a John A. Lamberton Research Scholarship (fellowship to A.M.G.) is kindly acknowledged.

\section{Conflict of Interest}

The authors declare no conflict of interests. 
Keywords: antibiotics $\cdot$ antimicrobial resistance $\cdot$ macrocyclic peptides $\cdot$ medicinal chemistry $\cdot$ peptides

[1] J. O'Neill, et al. Tackling drug-resistant infections globally: final report and recommendations. Review on Antimicrobial Resistance. (Wellcome Trust, London, UK, 2016).

[2] M. Mahlapuu, J. Hakansson, L. Ringstad, and C. Bjorn, Front. Cell. Infect. Microbiol. 2016, 6, 2235-2988.

[3] J. Z. Acedo, S. Chiorean, J. C. Vederas, and M. J. van Belkum. FEMS Microbiol. Rev. 2018, 42, 805-828.

[4] S. A. Cochrane, and J. C. Vederas. Med. Res. Rev. 2016. 36, 4-31.

[5] L. L. Ling, et al. Nature. 2015, 517, 455-159.

[6] A. M. Giltrap, et al. Org. Lett. 2016, 18, 2788-2791.

[7] K. Jin, et al. Nat Commun. 2016, 7, 12394.

[8] V. Ng, S. A. Kuehne, and W. C. Chan. Chem. Eur. J. 2018, 24, 91369147.

[9] E. J. Ramchuran, et al. Front. Microbiol. 2018, 9, 1535.

[10] Y. Zong, et al. J. Med. Chem. 2018, 61, 3409-3421.

[11] K. H. Chen, S. P. Le, X. Han, J. M. Frias, and J. S Nowick. Chem. Commun. 2017, 53, 11357-11359.

[12] A. Parmar, et al. Chem. Sci. 2017, 8, 8183-8192.
[13] P. Wen, J. M, Vanegas, S. B. Rempe, and E. Tajkhorshid. Chem. Sci. 2018, 9, 6997-7008.

[14] C. N. Lungu, and M. V. Diudea, Curr. Comput. Aided Drug Des. 2018, 14, 29-34.

[15] C. Öster, C. et al. Chem. Sci. 2018, 9, 8850-8859.

[16] H. Yang, M. Wierzbicki, D. R. Du Bois, and J. S. Nowick. J. Am. Chem Soc. 2018, 140, 14028-14032.

[17] S. A. Cochrane, et al. Proc. Natl. Acad. Sci. U. S. A. 2016, 113, 1156111566.

[18] P. 't Hart, S. F. Oppedijk, E. Breukink, and N. I. Martin. Biochemistry. 2016, 55, 232-237.

[19] Y. Y. Dong, et al. Cell. 2018, 175, 1045.

[20] S. A. H. Abdel Monaim, et al. ACS Omega. 2016, 1, 1262-1265.

[21] S. A. Cochrane, and J. C. Vederas. Int. J. Antimicrob. Agents. 2014, 44, 493-499.

[22] M. Vaara. Molecules. 2019, 24, 249.

[23] M. Varra, and P. Viljanen. Antimicrob. Agents Chemother.1985, 27, 548-554.

[24] Methods for Dilution Antimicrobial Susceptibility Tests for Bacteria That Grow Aerobically; Clinical and Laboratory Standards Institute: Wayne, PA. 2011.

\section{For internal use, please do not delete. Submitted_Manuscript}




\section{Entry for the Table of Contents}

Layout 1:

\section{COMMUNICATION}

Mighty macrocycles: an in-depth look at the binding parameters of teixobactin, a macrocyclic antimicrobial peptide, with its membrane target, lipid II. Teixobactin binds to analogues of both Grampositive and Gram-negative bacterial lipids, allowing its activity scope to be extended to both types of organisms using membrane-disrupting peptides.

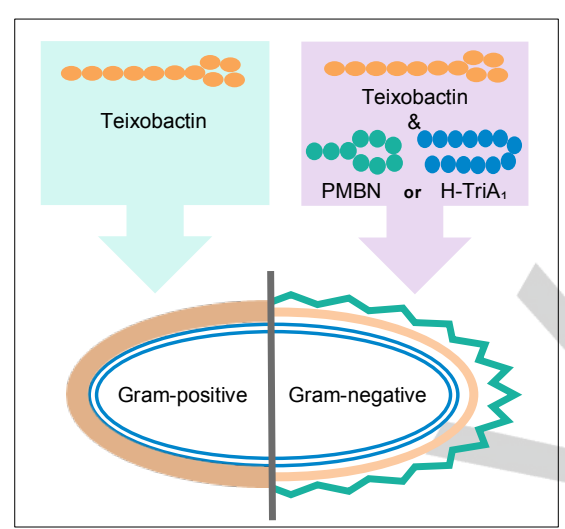

Sorina Chiorean, Isaac Antwi, Daniel W. Carney, loli Kotsogianni, Andrew M.

Giltrap, Francesca M. Alexander, Stephen A. Cochrane, Richard J. Payne, Nathaniel I. Martin, Antoine Henninot, and John C. Vederas*

Page No. - Page No.

Dissecting the binding interactions of teixobactin with the bacterial cell wall precursor lipid II 